\title{
Concordance Rates of Birth Defects After Assisted Reproductive Technology Among 17258 Japanese Twin Pregnancies: A Nationwide Survey, 2004-2009
}

\author{
Syuichi Ooki
}

Department of Health Science, Ishikawa Prefectural Nursing University, Kahoku, Ishikawa, Japan

Received May 28, 2012; accepted August 8, 2012; released online November 3, 2012

\begin{abstract}
Background: Most twins after assisted reproductive technology (ART) are dizygotic. Analysis of dizygotic twin pairs is useful in assessing familial aggregation in the development of birth defects.

Methods: Using nationwide post-ART data from the Japan Society of Obstetrics and Gynecology, recurrence risk ratios (RRRs) - defined as probandwise concordance rates of birth defects in twins divided by the prevalence of birth defects in the general population - were calculated as indicators of familial aggregation. Birth defects were then reclassified according to the ICD-10 categories corresponding to codes Q00-Q99. From 2004 to 2009, there were 17258 twin pregnancies.

Results: At least 1 birth defect was noted in 236 twin pairs: 11 concordant and 225 discordant pairs. Regarding major organ systems, high probandwise concordance rates were observed for congenital malformations of eye, ear, face, and neck (11.8\%), cleft lip and cleft palate (10.5\%), congenital malformations of the nervous system (9.8\%), and other congenital malformations of the digestive system (9.5\%). High RRRs were observed for congenital malformations of eye, ear, face, and neck $(R R R=233)$, specifically other congenital malformations of the ear $(R R R=449)$; congenital malformations of the great arteries $(R R R=235)$, specifically those of the patent ductus arteriosus $(R R R=530)$; and for cleft lip and cleft palate $(R R R=208)$, specifically cleft palate with cleft lip $(\mathrm{RRR}=609)$. The probandwise concordance rate of any birth defect $(8.9 \%)$ was nearly identical to the approximated recurrence risk of sib-pairs $(8.8 \%)$, which assumed multifactorial inheritance.
\end{abstract}

Conclusions: The present findings suggest that familial aggregation is a factor in some birth defects.

Key words: birth defects; assisted reproductive technology (ART); twin pairs; concordance rate; nationwide epidemiologic study

\section{INTRODUCTION}

According to data on assisted reproductive technology (ART) and vital statistics in Japan, the percentage of ART live births was $2.49 \%(26680 / 1070035)$ in 2009 , which indicates that ART is becoming widespread in Japan. ${ }^{1}$ To date, most population-based epidemiologic studies of twinning and birth defects view twins as individuals, not twin pairs. Zygosity determination of same-sex twin pairs is rarely performed at birth, and same-sex pairs are often regarded as monozygotic (MZ) twin pairs. This assumption necessarily underestimates the resemblance of $\mathrm{MZ}$ pairs according to the proportion of dizygotic (DZ) pairs.

Given these circumstances, ART data present a unique opportunity for twin studies, as most twins after ART are DZ.
The first step in genetic epidemiologic analyses is to clarify familial aggregation of targeted traits. To identify familial aggregation, it is important to compare the concordance rate of birth defects in DZ twin pairs (ie, siblings that develop together in the same womb) $)^{2,3}$ with the prevalence of birth defects in the general population. The present study used nationwide data on ART to calculate the concordance rate of twin pairs and examine familial aggregation of birth defects.

\section{METHODS}

\section{Outline of Japanese ART data}

The method for collecting data has been described elsewhere. ${ }^{4}$ Almost all medical institutions that perform ART are registered with the Japan Society of Obstetrics and Gynecology (JSOG). 
Starting in 2004, an annual list of all ART pregnancies resulting in birth defects has been presented in the JSOG annual ART reports (in Japanese). The author used these case report data from 2004-2009 as initial information. The items included are ART method, blastocyst transfer, maternal age, perinatal outcome and gestational week, plurality, sex, early neonatal infant death up to day 6, and disease name. Within the study period, there were 159451 singleton pregnancies, 17258 twin pregnancies, and 839 triplet/+ pregnancies.

Birth defects were reclassified according to the International Classification of Diseases, 10th edition (ICD-10), 2003 version. Diseases that were classified in the categories corresponding to ICD-10 codes Q00-Q99 (ie, congenital malformations, deformations, and chromosomal abnormalities) were selected and analyzed. In total, 1502 abortions, stillbirths, and live births with birth defects were included.

The present author paired twins, using information on birth year, maternal age, gestational weeks, ART method, blastocyst implantation, and plurality. Other information on twin status was also considered; for example, first- and second-born twins were clearly described and listed.

\section{Statistical analyses}

All concordant pairs were listed with their demographic data and neonatal outcome. The pairwise and probandwise concordance rates ${ }^{5}$ were then calculated for each major organ system category, each subcategory, and, in some cases, each disease.

In the present study, the terms "concordant pair" and "discordant pair" are used to describe the disease condition of a given twin pair. The pairwise concordance rate is the probability that both members of a twin pair are affected if at least 1 member of the pair is affected. The probandwise concordance rate is the probability that a twin is affected if his/ her co-twin is affected. Only probandwise concordance rates can be directly compared with risk rates reported for other familial pairings and with population prevalence figures. ${ }^{5}$ Pairwise concordance rates were calculated as $\mathrm{C} /(\mathrm{C}+\mathrm{D})$, and probandwise concordance rates as $2 \times \mathrm{C} /(2 \times \mathrm{C}+\mathrm{D})$, where $\mathrm{C}$ denotes the number of affected concordant pairs and $\mathrm{D}$ denotes the number of discordant pairs. ${ }^{5}$

Recurrence risk ratios (RRRs) ${ }^{6}$ were used as indicators of familial aggregation of birth defects and were calculated as the ratio of the risk of disease manifestation (which, given that one's relative is affected, correspond to the probandwise concordance rate of twin pairs in the present study) to the disease prevalence in the general population.

Moreover, the author estimated the recurrence risk of DZ pairs, which have the same genetic resemblance as sib-pairs. According to Edwards, ${ }^{7}$ if a targeted disease is determined by multifactorial inheritance, its frequency in sib-pairs or DZ twin pairs approximates the square root of disease prevalence in the general population. Thus, the present study compared the probandwise concordance rate of any birth defect in twin pairs with the estimated recurrence risk in sib-pairs and DZ pairs.

\section{RESULTS}

From among 247 twins with any birth defect, a total of 236 twin pairs were identified: 11 concordant and 225 discordant pairs. Thus, 1.4\% (236/17258) of twin pairs (pregnancies) had at least 1 affected member.

Demographic and perinatal outcome data for all concordant pairs are presented in Table 1. They comprise 6 male-male, 1 female-female, and 4 opposite-sex pairs. Two of the 11 pairs were stillbirth-stillbirth. The records for 6 of the 9 live-birth pairs showed no early neonatal infant death, although the outcome of the other 3 pairs is not known.

The calculated concordance rates and RRRs are shown in Table 2. Regarding classification by major organ system, relatively high probandwise concordance rates were observed for congenital malformations of eye, ear, face, and neck $(11.8 \%)$, cleft lip and cleft palate $(10.5 \%)$, congenital malformations of the nervous system $(9.8 \%)$, and other congenital malformations of the digestive system (9.5\%).

Among disease classifications with more than 10 total concordant/discordant twin pairs, RRRs were greater than 200 for congenital malformations of eye, ear, face, and neck $(\mathrm{RRR}=233)$, specifically other congenital malformations of ear $(\mathrm{RRR}=449)$; congenital malformations of the great arteries $(R R R=235)$, specifically those of the patent ductus arteriosus $(\mathrm{RRR}=530)$; and cleft lip and cleft palate $(\mathrm{RRR}=$ $208)$, specifically cleft palate with cleft lip $(R R R=609)$.

The probandwise concordance rate of any birth defect was $8.9 \%$, which was nearly identical to the estimated recurrence risk among sib-pairs and DZ pairs, namely, $8.8 \%$ (the square root of 0.77 , see Table 2).

\section{DISCUSSION}

\section{Method of analysis}

Correct zygosity diagnosis is rare in most studies of birth defects. Researchers have often compared resemblance between same-sex pairs (as a proxy for MZ pairs) and opposite-sex DZ pairs, on the assumption that there is no sex difference in prevalence. In the present study, information was obtained only from probands. In such a situation, the probandwise concordance rate is the second-best measure of resemblance in twin pairs.

Although most subjects in the present study were DZ pairs, some MZ pairs may well have also been included. According to a recent meta-analysis by Vitthala et $\mathrm{al}^{8}{ }^{8}$ the incidence of MZ twins after ART is 2.25 times that after natural conception. Caution is warranted in interpreting these values because most previous studies used the pairwise rather than the probandwise concordance rate. Ascertainment bias in the identification of twin pairs would be small in the present sample, since birth defects during pregnancy or the neonatal period (at the latest) were reported in the same hospital. However, this ascertainment period may underestimate the 
Ooki S.

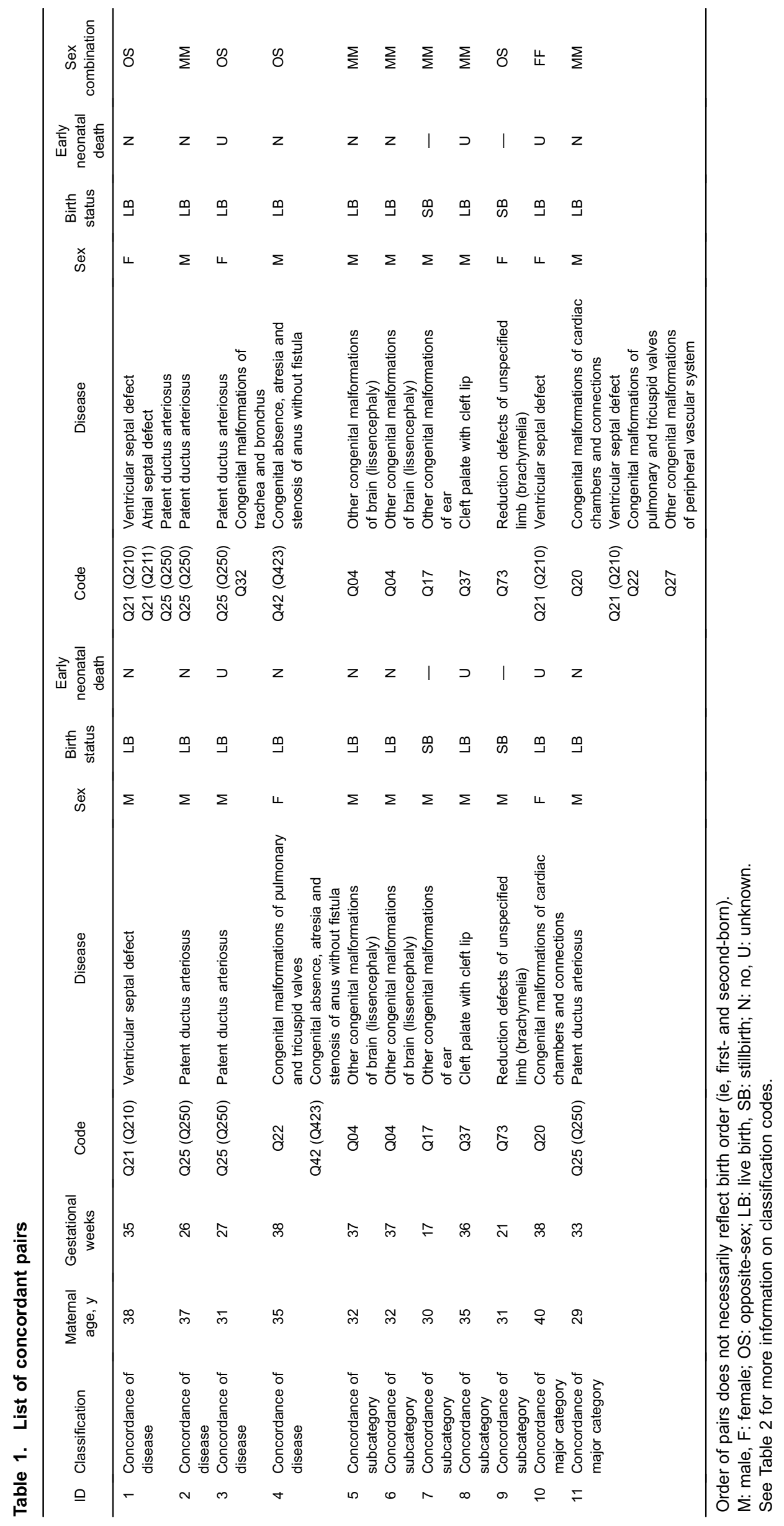


Table 2. Concordance rates in twin pairs and recurrence risk ratios (RRRs) for birth defects

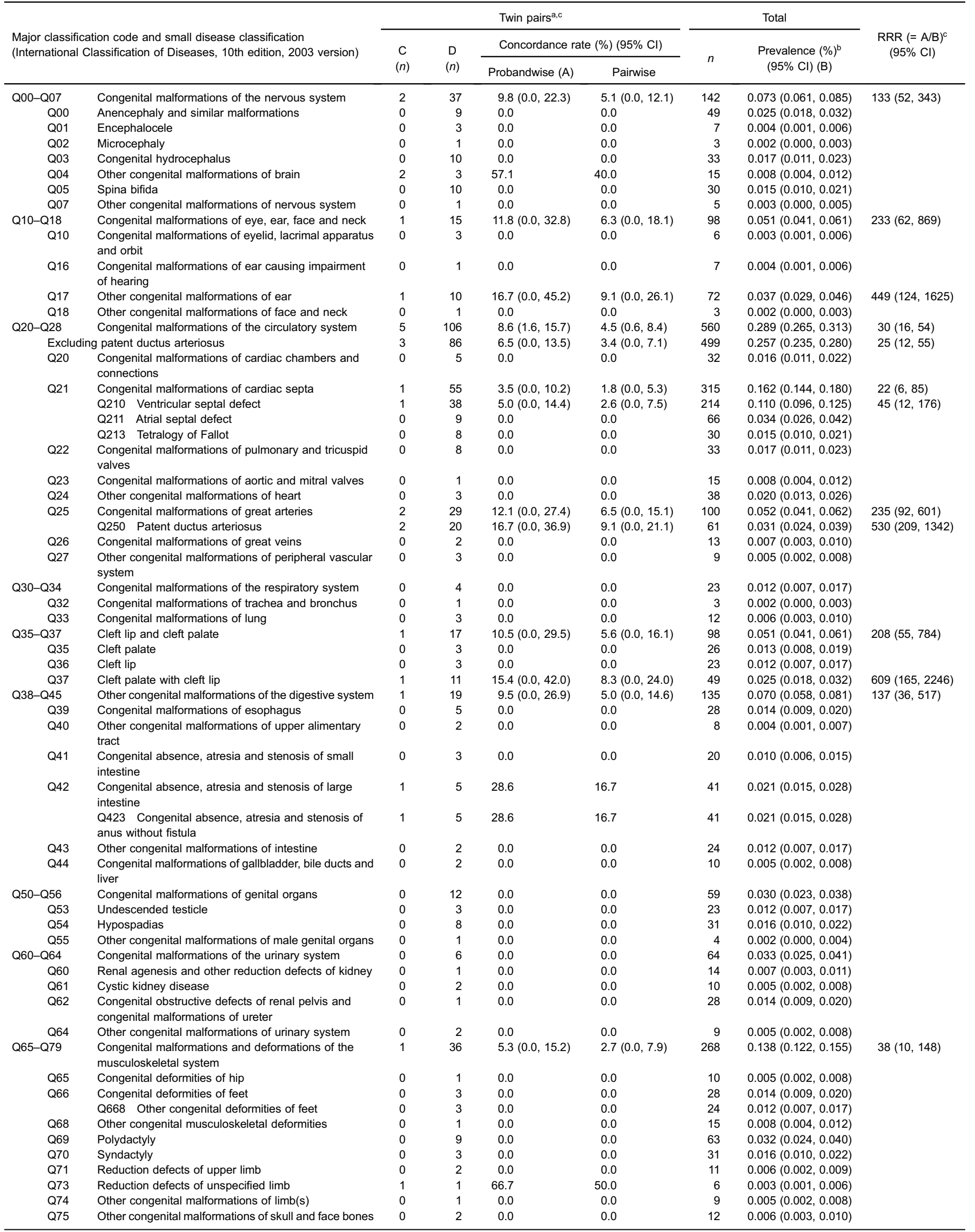




\begin{tabular}{|c|c|c|c|c|c|c|c|c|}
\hline \multirow{3}{*}{\multicolumn{2}{|c|}{$\begin{array}{l}\text { Major classification code and small disease classification } \\
\text { (International Classification of Diseases, 10th edition, } 2003 \text { version) }\end{array}$}} & \multicolumn{4}{|c|}{ Twin pairs ${ }^{a, c}$} & \multirow{3}{*}{\multicolumn{2}{|c|}{$\begin{array}{l}\text { Total } \\
\text { Prevalence }(\%)^{b} \\
(95 \% \mathrm{Cl})(\mathrm{B})\end{array}$}} & \multirow{3}{*}{$\begin{array}{l}\mathrm{RRR}(=\mathrm{A} / \mathrm{B})^{\mathrm{c}} \\
\quad(95 \% \mathrm{Cl})\end{array}$} \\
\hline & & \multirow{2}{*}{$\begin{array}{l}\mathrm{C} \\
(n)\end{array}$} & \multirow{2}{*}{$\begin{array}{l}\mathrm{D} \\
(n)\end{array}$} & \multicolumn{2}{|c|}{ Concordance rate $(\%)(95 \% \mathrm{Cl})$} & & & \\
\hline & & & & Probandwise $(\mathrm{A})$ & Pairwise & & & \\
\hline Q77 & $\begin{array}{l}\text { Osteochondrodysplasia with defects of growth of } \\
\text { tubular bones and spine }\end{array}$ & 0 & 1 & 0.0 & 0.0 & 7 & $0.004(0.001,0.006)$ & \\
\hline \multirow[t]{3}{*}{ Q79 } & $\begin{array}{l}\text { Congenital malformations of the musculoskeletal } \\
\text { system, not elsewhere classified }\end{array}$ & 0 & 12 & 0.0 & 0.0 & 55 & $0.028(0.021,0.036)$ & \\
\hline & Q790 Congenital diaphragmatic hernia & 0 & 4 & 0.0 & 0.0 & 20 & $0.010(0.006,0.015)$ & \\
\hline & Q792 Exomphalos & 0 & 5 & 0.0 & 0.0 & 19 & $0.010(0.005,0.014)$ & \\
\hline Q80-Q89 & Other congenital malformations & 0 & 14 & 0.0 & 0.0 & 68 & $0.035(0.027,0.043)$ & \\
\hline Q82 & Other congenital malformations of skin & 0 & 2 & 0.0 & 0.0 & 20 & $0.010(0.006,0.015)$ & \\
\hline Q85 & Phakomatoses, not elsewhere classified & 0 & 1 & 0.0 & 0.0 & 2 & $0.001(0.000,0.002)$ & \\
\hline Q87 & $\begin{array}{l}\text { Other specified congenital malformation syndromes } \\
\text { affecting multiple systems }\end{array}$ & 0 & 8 & 0.0 & 0.0 & 20 & $0.010(0.006,0.015)$ & \\
\hline \multirow[t]{2}{*}{ Q89 } & $\begin{array}{l}\text { Other congenital malformations, not elsewhere } \\
\text { classified }\end{array}$ & 0 & 3 & 0.0 & 0.0 & 25 & $0.013(0.008,0.018)$ & \\
\hline & $\begin{array}{l}\text { Q897 Multiple congenital malformations, not elsewhere } \\
\text { classified }\end{array}$ & 0 & 1 & 0.0 & 0.0 & 11 & $0.006(0.002,0.009)$ & \\
\hline Q90-Q99 & Chromosomal abnormalities, not elsewhere classified & 0 & 27 & 0.0 & 0.0 & 288 & $0.148(0.131,0.166)$ & \\
\hline Q90 & Down's syndrome & 0 & 19 & 0.0 & 0.0 & 178 & $0.092(0.078,0.105)$ & \\
\hline \multirow[t]{3}{*}{ Q91 } & Edwards' syndrome and Patau's syndrome & 0 & 8 & 0.0 & 0.0 & 72 & $0.037(0.029,0.046)$ & \\
\hline & Q913 Edwards' syndrome, unspecified & 0 & 5 & 0.0 & 0.0 & 57 & $0.029(0.022,0.037)$ & \\
\hline & Q917 Patau's syndrome, unspecified & 0 & 3 & 0.0 & 0.0 & 15 & $0.008(0.004,0.012)$ & \\
\hline \multicolumn{2}{|c|}{ Any birth defects } & 11 & 225 & $8.9(4.0,13.8)$ & $4.7(2.0,7.4)$ & 1493 & $0.770(0.731,0.809)$ & $12(8,17)$ \\
\hline \multicolumn{2}{|c|}{ Excluding patent ductus arteriosus } & 9 & 205 & $8.1(3.1,13.0)$ & $4.2(1.5,6.9)$ & 1432 & $0.738(0.700,0.776)$ & $11(7,17)$ \\
\hline
\end{tabular}

Singleton pregnancies $=159451 ;$ twin pregnancies $=17258$; total fetuses $/$ neonates $=193967$.

C: concordant twin pair, D: discordant twin pair.

${ }^{a}$ Only twin pairs with at least 1 affected member are listed.

bTotal prevalence was calculated per fetuses/neonates.

${ }^{\mathrm{c}}$ Concordance rates and RRRs with their $95 \% \mathrm{Cl}$ were calculated for disease classifications that had $>10$ total concordant/discordant twin pairs and a concordance rate not equal to 0 .

concordance rate if pairs differed in the age when symptoms of birth defects became obvious.

\section{Birth defects in twin pairs}

The number of concordant pairs was clearly higher for male-male pairs than for female-female and opposite-sex pairs. No previous study reported that concordance rates differed according to the sex combination of twin pairs.

The concordance rates of birth defects in twin pairs, as determined in previous large studies, are shown in Table 3. The concordance rate for any birth defect is higher in $\mathrm{MZ}$ pairs and all twin pairs as compared with DZ pairs and oppositesex DZ pairs, ${ }^{9-12}$ respectively, which suggests a genetic contribution to birth defects. The probandwise concordance rate of any birth defect $(8.9 \%)$ was nearly identical to the estimated recurrence risk among sib-pairs (8.8\%) and much higher than the prevalence in the general population $(0.77 \%)$. These results suggest familial aggregation of birth defects and that the origin of this aggregation is multifactorial inheritance.

The probandwise concordance rate of congenital malformations of the circulatory system was 30 -fold higher than the prevalence in the general population. Kenna et $\mathrm{al}^{13}$ found 2 concordant pairs out of $15 \mathrm{MZ}$ pairs and 2 concordant pairs with different heart lesions out of DZ 12 pairs. According to Hardin et $\mathrm{al},{ }^{14}$ the probandwise concordance rate for oppositesex DZ twin pairs was $14.0 \%$. A small number of studies directly compared the recurrence risk of twin pairs with that of first-degree relatives. Caputo et $\mathrm{al}^{2}$ compared recurrence risk in DZ pairs and sib-pairs and concluded that the higher recurrence and concordance of congenital heart disease in DZ twins might depend on a poorly understood environmental risk during pregnancy. However, Øyen et $\mathrm{al}^{15}$ found that intrauterine conditions had no effect, after comparing the RRRs of opposite-sex twin pairs and first-degree relatives.

It has been suggested that patent ductus arteriosus (PDA) is related to prematurity and is consequently more prevalent in twins. ${ }^{16-18}$ Layde et al $^{19}$ found that a high concordance rate was observed in same-sex pairs, which suggests both a strong genetic component to the etiology of PDA and high rates of prematurity in twin pairs. The present finding of a high concordance rate and RRR for PDA supports the genetic/ shared environmental hypothesis. When concordance rates were calculated after excluding PDA cases, the results were not markedly different, as shown in Table 2 .

Regarding congenital malformations of the nervous system in twins, neural tube defects have been well examined. ${ }^{10,12,20-25}$ The present study observed no concordant pair with anencephalus, spina bifida, or hydrocephalus. There were 2 male-male concordant pairs with lissencephaly (subcategory Q04), but no other such cases among twins or singletons, suggesting that the original data were incorrectly input.

One male-male concordant pair showed both micrognathia and low-set ear (subcategory Q17). There is no populationbased twin study of these defects.

There was one male-male concordant pair who had cleft palate with cleft lip (subcategory Q37), with a $15.4 \%$ 
Table 3. Concordance rates of birth defects in previously published twin studies

\begin{tabular}{|c|c|c|c|c|c|c|c|c|c|}
\hline \multirow[b]{2}{*}{ Birth defects } & \multirow[b]{2}{*}{ Author(s) } & \multirow[b]{2}{*}{$\begin{array}{l}\text { Year of data } \\
\text { collection }\end{array}$} & \multirow[b]{2}{*}{ No. of pairs } & \multirow[b]{2}{*}{ Data source } & \multirow[b]{2}{*}{ Zygosity } & \multicolumn{2}{|c|}{ Twin pairs } & \multicolumn{2}{|c|}{ Concordance rate $(\%)$} \\
\hline & & & & & & $\begin{array}{l}\text { Concordant } \\
(n \text { pairs })\end{array}$ & $\begin{array}{l}\text { Discordant } \\
\text { (n pairs) }\end{array}$ & Probandwise & Pairwise \\
\hline \multirow[t]{6}{*}{ Any birth defect } & \multirow[t]{2}{*}{ Myrianthopoulos [1976] ${ }^{9}$} & \multirow[t]{2}{*}{ Not mentioned } & \multirow[t]{2}{*}{615} & \multirow{2}{*}{$\begin{array}{l}\text { Collaborative perinatal } \\
\text { project }\end{array}$} & $M Z^{a}$ & 23 & 46 & 50.0 & 33.3 \\
\hline & & & & & $\mathrm{D} z^{\mathrm{a}}$ & 6 & 79 & 13.2 & 7.1 \\
\hline & Imaizumi et al $[1990]^{10}$ & 1974 & 12392 & Population-based & All & 22 & 34 & 56.4 & 39.3 \\
\hline & \multirow[t]{2}{*}{ Kato \& Fujiki [1992] $]^{11}$} & \multirow[t]{2}{*}{$1979-1990$} & \multirow[t]{2}{*}{968} & \multirow[t]{2}{*}{ Hospital-based } & All & 3 & 39 & 13.3 & 7.1 \\
\hline & & & & & OS & 0 & 8 & 0.0 & 0.0 \\
\hline & Campana \& Roubicek [1996] ${ }^{12}$ & 1982-1995 & 690 & Hospital-based & All & 5 & 25 & 28.6 & 16.7 \\
\hline \multicolumn{10}{|c|}{ Congenital malformations of the nervous system } \\
\hline neural tube defects & Janerich \& Piper $[1978]^{23}$ & $1961-1974$ & 23310 & Population-based & All & 4 & 55 & 12.7 & 6.8 \\
\hline anencephalus & Imaizumi [1978] ${ }^{21}$ & 1969-1976 & Not mentioned & Death certificate & All & 9 & 100 & 15.3 & 8.3 \\
\hline neural tube defects & Windham \& Sever [1982] ${ }^{24}$ & 1966-1972 & 8440 & Population-based & All & 1 & 26 & 7.1 & 3.7 \\
\hline hydrocephalus & Imaizumi $[1989]^{22}$ & 1969-1985 & Not mentioned & Death certificate & All & 16 & 91 & 26.0 & 15.0 \\
\hline anencephalus & Imaizumi et al $[1990]^{10}$ & 1974 & 12392 & Population-based & All & 4 & 8 & 50.0 & 33.3 \\
\hline hydrocephalus & Imaizumi et al $[1990]^{10}$ & 1974 & 12392 & Population-based & All & 3 & 10 & 37.5 & 23.1 \\
\hline anencephalus & Campana \& Roubicek [1996] ${ }^{12}$ & 1982-1995 & 690 & Hospital-based & All & 4 & 27 & 22.9 & 12.9 \\
\hline \multirow[t]{2}{*}{ neural tube defects } & \multirow[t]{2}{*}{ Deak et al $[2008]^{25}$} & \multirow[t]{2}{*}{ 1993-2007 } & \multirow[t]{2}{*}{47} & \multirow[t]{2}{*}{ Many data sources } & $M Z^{b}$ & 2 & 3 & 57.1 & 40.0 \\
\hline & & & & & $\mathrm{D} Z^{\mathrm{b}}$ & 3 & 32 & 15.8 & 8.6 \\
\hline \multicolumn{10}{|c|}{ Congenital malformations of the circulatory system } \\
\hline $\begin{array}{l}\text { same congenital heart } \\
\text { disease }\end{array}$ & Kenna et al $[1975]^{13}$ & $1960-1969$ & Not mentioned & Population-based & $\mathrm{MZ}^{\mathrm{c}}$ & 2 & 13 & 23.5 & 13.3 \\
\hline $\begin{array}{l}\text { any congenital heart } \\
\text { disease }\end{array}$ & Kenna et al $[1975]^{13}$ & $1960-1970$ & Not mentioned & Population-based & $\mathrm{DZ}{ }^{\mathrm{c}}$ & 2 & 10 & 28.6 & 16.7 \\
\hline patent ductus arteriosus & Layde et al $[1980]^{19}$ & $1969-1976$ & 1670 twins & Population-based & All & 7 & 14 & 50.0 & 33.3 \\
\hline congenital heart disease & Caputo et al $[2005]^{2}$ & 1999-2002 & 66 & Patient enrollment & $\mathrm{D} Z^{\mathrm{d}}$ & 9 & 57 & 24.0 & 13.6 \\
\hline cardiovascular defects & Hardin et al $[2009]^{14}$ & $1983-2003$ & 56709 & Birth defect monitoring & All & 331 & 2404 & 21.6 & 12.1 \\
\hline & & & & & os & 53 & 650 & 14.0 & 7.5 \\
\hline ventricular septal defect & Hardin et al $[2009]^{14}$ & 1983-2003 & 56709 & Birth defect monitoring & All & 4 & 110 & 6.8 & 3.5 \\
\hline & & & & & $M Z^{e}$ & 4 & 87 & 8.4 & 4.4 \\
\hline & & & & & $\mathrm{DZ} Z^{\mathrm{e}}$ & 0 & 23 & 0.0 & 0.0 \\
\hline Cleft lip and cleft palate & & & & & & & & & \\
\hline cleft lip/palate & Lin et al $[1999]^{26}$ & $1977-1997$ & 38 & Hospital-based & $M Z^{f}$ & 4 & 3 & 72.7 & 57.1 \\
\hline & & & & & $\mathrm{DZ}{ }^{\mathrm{f}}$ & 1 & 10 & 16.7 & 9.1 \\
\hline cleft lip with/without cleft palate & Grosen et al $[2011]^{3}$ & 1936-2004 & 130710 & Population-based & $\mathrm{MZ}^{\mathrm{g}}$ & 8 & 16 & 50.0 & 33.3 \\
\hline & & & & & $\mathrm{DZ}^{\mathrm{g}}$ & 4 & 93 & 7.9 & 4.1 \\
\hline cleft palate & Grosen et al $[2011]^{3}$ & 1936-2004 & 130710 & Population-based & $M Z^{g}$ & 1 & 4 & 33.3 & 20.0 \\
\hline & & & & & $\mathrm{DZ}^{\mathrm{g}}$ & 1 & 25 & 7.4 & 3.8 \\
\hline Other congenital malformations of the & e digestive system & & & & & & & & \\
\hline esophageal atresia & David \& O'Callaghan [1975] $]^{27}$ & 1942-1973 & 19 & Hospital-based & All & 2 & 17 & 19.0 & 10.5 \\
\hline esophageal atresia & Orford et al $[2000]^{28}$ & 1948-1998 & 51 & Hospital-based & All & 2 & 47 & 7.8 & 4.1 \\
\hline Congenital malformations and deform & nations of the musculoskeletal sy & ystem & & & & & & & \\
\hline $\begin{array}{l}\text { Bochdalek diaphragmatic } \\
\text { hernia }\end{array}$ & Pober et al $[2005]^{30}$ & $\begin{array}{l}1972-1974 \\
1979-2003\end{array}$ & 8 & Hospital-based & All & 0 & 8 & 0.0 & 0.0 \\
\hline
\end{tabular}

Most probandwise concordance rates were recalculated by using the number of concordant and discordant pairs in the literature.

MZ: monozygotic, DZ: dizygotic, OS: opposite-sex

${ }^{a}$ blood type and placenta, ${ }^{b}$ maternal report, ${ }^{\mathrm{c}}$ placentation and chorionicity, ${ }^{\mathrm{d}}$ blood type, chorionicity, physical characteristics, ${ }^{\mathrm{e}}$ placenta and reported type, fblood type, physical resemblance, chorionicity, ${ }^{9}$ questionnaire.

probandwise concordance rate. This value is similar to that of DZ pairs (16.7\%), as reported by Lin et al. ${ }^{26}$ According to Grosen et al, ${ }^{3}$ the probandwise concordance rate for cleft lip/cleft palate was higher for MZ pairs than for DZ pairs. However, they also found that the recurrence risk for both types of clefts was greater in DZ twins than in nontwin siblings, suggesting intrauterine environmental effects on these traits. The fact that the RRR for cleft palate with cleft lip was highest in the present study supports their results.

There was no concordant pair with esophageal atresia (subcategory Q39). David and O'Callaghan ${ }^{27}$ found that the probandwise concordance rate for this condition was $19.0 \%$, although Orford et $\mathrm{al}^{28}$ reported a low pairwise concordance rate $(4.1 \%)$. There was 1 concordant opposite-sex DZ pair of imperforate anus (subcategory Q42). Källén ${ }^{17}$ reported that for alimentary atresia, including imperforate anus, concordance was rather common among same-sex pairs.

There was 1 concordant opposite-sex DZ pair with brachymelia (subcategory Q73). Métneki et $\mathrm{al}^{29}$ studied the occurrence of congenital limb reduction defects in twins and concluded that genetic factors have a limited role in pathogenesis. Pober et $a^{30}$ conducted a large twin study of Bochdalek diaphragmatic hernia, including 8 twin cases with no concordant pairs. The concordance rate of congenital malformations and deformations of the musculoskeletal system was low in the present study, in contrast to the relatively high prevalence among the general population.

\section{Limitations}

Most limitations of this study are due to deficiencies in the data collection system. The first limitation was the lack of a 
zygosity classification for same-sex pairs. Second, pairing of twins was not necessarily complete. Some concordant pairs might not have been real twin pairs. Third, the statistical power of the analyses was limited. The present concordance rates might be strongly influenced by chance factors, since most disease concordance rates were calculated on the basis of no or 1 concordant pair.

\section{Conclusions}

The present results provide a good overview of concordance rates among twin pairs with birth defects after ART. Strong familial aggregation was observed for some birth defects.

\section{ACKNOWLEDGMENTS}

The author would like to thank Toshimi Ooma for assistance with data analysis. This work was supported in part by a Grant-in-Aid for Challenging Exploratory Research from the Japan Society for the Promotion of Science (Grant Number 23659356).

Conflicts of interest: None declared.

\section{ONLINE ONLY MATERIALS}

The Japanese-language abstract for articles can be accessed by clicking on the tab labeled Supplementary materials at the journal website http://dx.doi.org/10.2188/jea.JE20120103.

\section{REFERENCES}

1. Ooki S. Estimation of the contribution of assisted and nonassisted reproductive technology fertility treatments to multiple births during the past 30 years in Japan: 1979-2008. Twin Res Hum Genet. 2011;14:476-83.

2. Caputo S, Russo MG, Capozzi G, Morelli C, Argiento P, Di Salvo $G$, et al. Congenital heart disease in a population of dizygotic twins: an echocardiographic study. Int J Cardiol. 2005;102:293-6.

3. Grosen D, Bille C, Petersen I, Skytthe A, Hjelmborg Jv, Pedersen JK, et al. Risk of oral clefts in twins. Epidemiology. 2011;22:313-9.

4. Ooki S. Birth defects in singleton versus multiple ART births in Japan (2004-2008). J Pregnancy. 2011;2011:285706.

5. McGue M. When assessing twin concordance, use the probandwise not the pairwise rate. Schizophr Bull. 1992;18:171-6.

6. Guo SW. Inflation of sibling recurrence-risk ratio, due to ascertainment bias and/or overreporting. Am J Hum Genet. 1998;63:252-8.

7. Edwards JH. The simulation of mendelism. Acta Genet Stat Med. 1960;10:63-70.

8. Vitthala S, Gelbaya TA, Brison DR, Fitzgerald CT, Nardo LG. The risk of monozygotic twins after assisted reproductive technology: a systematic review and meta-analysis. Hum Reprod Update. 2009;15:45-55.

9. Myrianthopoulos NC. Congenital malformations in twins. Acta
Genet Med Gemellol (Roma). 1976;25:331-5.

10. Imaizumi Y, Asaka A, Inouye E. Fetal deaths with birth defects among Japanese multiples, 1974. Acta Genet Med Gemellol (Roma). 1990;39:345-50.

11. Kato K, Fujiki K. Multiple births and congenital anomalies in Tokyo Metropolitan Hospitals, 1979-1990. Acta Genet Med Gemellol (Roma). 1992;41:253-9.

12. Campana MA, Roubicek MM. Maternal and neonatal variables in twins: an epidemiological approach. Acta Genet Med Gemellol (Roma). 1996;45:461-9.

13. Kenna AP, Smithells RW, Fielding DW. Congenital heart disease in Liverpool: 1960-69. Q J Med. 1975;44:17-44.

14. Hardin J, Carmichael SL, Selvin S, Lammer EJ, Shaw GM. Increased prevalence of cardiovascular defects among 56,709 California twin pairs. Am J Med Genet A. 2009;149A:877-86.

15. Øyen N, Poulsen G, Boyd HA, Wohlfahrt J, Jensen PK, Melbye M. Recurrence of congenital heart defects in families. Circulation. 2009;120:295-301.

16. Pinborg A, Loft A, Rasmussen S, Schmidt L, Langhoff-Roos J, Greisen G, et al. Neonatal outcome in a Danish national cohort of $3438 \mathrm{IVF} / \mathrm{ICSI}$ and 10,362 non-IVF/ICSI twins born between 1995 and 2000. Hum Reprod. 2004;19:435-41.

17. Källén B. Congenital malformations in twins: a population study. Acta Genet Med Gemellol (Roma). 1986;35:167-78.

18. Bergh T, Ericson A, Hillensjö T, Nygren KG, Wennerholm UB. Deliveries and children born after in-vitro fertilisation in Sweden 1982-95: a retrospective cohort study. Lancet. 1999;354: 1579-85.

19. Layde PM, Erickson JD, Falek A, McCarthy BJ. Congenital malformation in twins. Am J Hum Genet. 1980;32:69-78.

20. Rogers SC. Anencephalus, Spina Bifida, twins, and teratoma. Br J Prev Soc Med. 1976;30:26-8.

21. Imaizumi Y. Concordance and discordance of anencephaly in 109 twin pairs in Japan. Jinrui Idengaku Zasshi. 1978;23:389-93.

22. Imaizumi Y. Concordance and discordance of congenital hydrocephalus in 107 twin pairs in Japan. Teratology. 1989;40:101-3.

23. Janerich DT, Piper J. Shifting genetic patterns in anencephaly and spina bifida. J Med Genet. 1978;15:101-5.

24. Windham GC, Sever LE. Neural tube defects among twin births. Am J Hum Genet. 1982;34:988-98.

25. Deak KL, Siegel DG, George TM, Gregory S, Ashley-Koch A, Speer MC; NTD Collaborative Group. Further evidence for a maternal genetic effect and a sex-influenced effect contributing to risk for human neural tube defects. Birth Defects Res A Clin Mol Teratol. 2008;82:662-9.

26. Lin YC, Lo LJ, Noordhoff MS, Chen YR. Cleft of the lip and palate in twins. Changgeng Yi Xue Za Zhi. 1999;22:61-7.

27. David TJ, O'Callaghan SE. Oesophageal atresia in the South West of England. J Med Genet. 1975;12:1-11.

28. Orford J, Glasson M, Beasley S, Shi E, Myers N, Cass D. Oesophageal atresia in twins. Pediatr Surg Int. 2000;16:541-5.

29. Métneki J, Czeizel AE, Evans JA. Congenital limb reduction defects in twins. Eur J Pediatr. 1996;155:483-90.

30. Pober BR, Lin A, Russell M, Ackerman KG, Chakravorty S, Strauss B, et al. Infants with Bochdalek diaphragmatic hernia: sibling precurrence and monozygotic twin discordance in a hospital-based malformation surveillance program. Am J Med Genet A. 2005;138A:81-8. 